Running head: POSITIVE SEMIOTICS

\title{
Positive Semiotics
}

\section{Tim Lomas}

\section{Review of General Psychology}

Note: This is not the final version of the article in the Review of General Psychology.

It is not the copy of record. 


\begin{abstract}
Although semiotics has historically been a focus of interest in psychology, its impact over recent decades has been fairly muted. Moreover, no systematic efforts have been made to study and understand it from a positive perspective, i.e., the way sign-systems are or can be "positive." As such, this paper introduces the notion of "positive semiotics," a label for the disparate research and theorising that is already underway across academia relating to this topic. The paper draws on the work of C. S. Peirce, particularly in terms of his triadic view of sign-systems as comprising a sign, an object, and an interpretant. The idea of positivity is then elucidated using the criterion of desirability, drawing on the work of James Pawelski. Attempts are also made to ascertain the nature of desirability, including normative forms (clarified here using the conceptual triad of goodness, truth, and beauty) and non-normative forms (understood as personal wants). The paper then considers four key semiotic channels discursive language, body language, symbols, and art - looking at selective examples of how positive semiotics might pertain to that channel. It is hoped the paper will stimulate further interest in, and work on, a phenomenon that is of considerable importance to psychology and beyond.
\end{abstract}

Keywords: language; semiotics; wellbeing; positive psychology 


\section{Positive Semiotics}

Semiotics and psychology share a common origin in the philosophy of mind (Bouissac, 1998). Moreover, as general psychology emerged as a distinct academic field in the $19^{\text {th }}$ century, semiotics was regarded by theorists such as De Saussure (1916) - who referred to it as "semiology" - as being encompassed within psychology as an integral part. However, following the cognitive revolution in psychology, the fields have largely separated and entered a more adversarial relationship (or at best operating in parallel) (Bouissac, 1998). Psychology has seen trends towards the dominance of brain sciences and computational models, while from the other direction semioticians have largely disdained the methods and aims of experimental psychology. As a result, academics interested in semiotics tend to be connected more with disciplines such as linguistics, literary studies, art, sociology, and philosophy. However, this paper makes the case that much can be gained from a rapprochement of psychology and semiotics - as some others have also sought to do (e.g., Cornejo, 2004) - and offers some suggestions for how they might enter into useful dialogue and collaboration.

While recognising that such rapprochement could take various forms, to limit this discussion to a manageable area of enquiry, this paper will introduce and focus on the notion of positive semiotics (PS). Influenced by the emergent discipline of positive psychology (Seligman \& Csikszentmihalyi, 2000), PS is broadly concerned with the intersection between semiotics and wellbeing. In that respect, it seeks to explore and incorporate disparate research and theorising that is already underway in psychology, as well as in related academic fields (from sociology to anthropology). The choice to focus specifically on wellbeing is considered valid and timely, given the emergent understanding of the vital role that communication plays in wellbeing, particularly given the recent cultural prominence and impact of social media (Best, Manktelow, \& Taylor, 2014). 
Running head: POSITIVE SEMIOTICS

The starting point of PS is that semiotics is all pervasive. Essentially, everything can be regarded as a sign. As Chandler (2017) puts it, semiotics "embraces the whole field of signification, including 'life, the universe, and everything"' (p.xvi). We are drenched, saturated in text, in that everything around us can be "read for meaning" (Hendricks, 2016). As Derrida (1987, p.158) famously wrote, there is "nothing outside the text" (or literally, "Il n'y a pas de hors-texte" ["There is no outside-text"]). That is, texts do not only, or even primarily, involve discursive language. Anything can function as a sign - from the way a smile suggests happiness, to a thundercloud portending a coming storm. Given that, it is valuable to pay attention to the potential for "positive semiotics" - to the way in which sign systems are or can be positive. We shall explore this latter term in detail below, but suffice to say now that it broadly pertains to wellbeing, as filtered through the prism of normative and personal desirability. PS, then, is concerned with the study of our sign systems inasmuch as they reflect these positive attributes, and moreover the betterment of such systems so that they more strongly reflect them. To that end, the paper will consider numerous sign systems below, focusing on four broad semiotic "channels": discursive language; body language; symbols; and art. Before that, we shall clarify what we mean by semiotics, and after that, the notion of the positive.

\section{Semiotics}

A useful prism through which we can understand semiotics is the work of Charles Sanders Peirce (1839-1914). Peirce of course is not the only theorist one could invoke and harness in this task: other prominent candidates include De Saussure (1916), Ogden and Richards (1923), Morris (1938), Langer (1953), Baudrillard (1972), Eco (1976), and Barthes (1982). However, to provide clarity in this paper it was felt prudent to select and utilise one model of semiotics (rather than complicating the discussion by invoking competing theories). To that end, Peirce was selected as arguably still the foremost and most influential theorist in this 
Running head: POSITIVE SEMIOTICS

area, whose work is still widely used and discussed (Hervey, 2016). Peirce's (1998) theory of semiotics constitutes a theory of meaning, featuring three inter-related parts: a sign, an object, and an interpretant. (Peirce sometimes also used "sign" to refer to this tripartite configuration collectively, as well as for one of the constituent parts, the latter of which he also called the "representamen." To avoid confusion, we shall refer to the constituent part as the "sign," and the tripartite configuration as the "sign-system"). Thus, the sign is a signifier, i.e., "something which stands to somebody for something in some respect or capacity" (Peirce, 1955, p.99). This could be anything, from a facial expression (e.g., a smile) to a weather event (e.g., a lightning bolt). The object is the phenomenon signified by the sign. Thus, a smile might signify a state of happiness, and lightening an immanent storm. Finally, given that there is neither a fixed nor one-to-one correspondence between objects and signs - i.e., a given sign can potentially indicate or represent many objects, with patterns of signification changing fluidly across persons, contexts, and times - the interpretant is a person who attempts to decode the meaning of the sign. In the case of a smile, for instance, this means working out exactly what this means (e.g., is it a gesture of friendliness, seduction, placation, etc.). The identification of the interpretant was a particular innovation of Peirce (Reybrouck, 2004): in contrast to previously-dominant dyadic theories of meaning (which focused on relations between signifier and signified), Peirce's "triadic" theory highlighted the crucial role of the "sign-user" in decoding the meaning of a sign.

A further innovation of Peirce was differentiating between three different types of sign: icons, indices, and symbols. For Peirce, objects "determine" their signs, whereby it is possibly to classify signs according to whether they function by virtue of qualities (icons), existential facts (indices), or conventions (symbols). Thus icons, also known as "likenesses," are those which share some obvious likeness with their object. Examples include emoticons, diagrams (e.g., a building blueprint), no-smoking signs, photos, and computer icons (e.g., the 
Running head: POSITIVE SEMIOTICS

trash folder). In Peirce's (1982) words, these are connected to an object via "a mere community in some quality" (p.56). By contrast, indices are signs "whose relation to their objects consists in a correspondence in fact" (p.56), i.e., when a sign "naturally" correlates with or points to a particular object. Examples include facial expressions (e.g., a smile conveying happiness), environmental events (e.g., lightning denoting a storm), pointing fingers, proper names, and signals (e.g., a smoke alarm signifying fire). Finally, symbols are those "whose relation to their objects is an imputed character," i.e., according to convention or social agreement. Examples includes words (and language more generally), logos, and flags. It may not always be obvious which type a given sign is; indeed, Peirce acknowledged that most signs may be a combination of the various types. For instance, onomatopoeic words might be regarded as an icon (i.e., sharing a likeness with their object), an index (e.g., learned via pointing), and a symbol (i.e., being somewhat a matter of convention).

As a general heuristic, Peirce's schema will be helpful in our analysis of PS here. For a start, his tripartite classification of signs (into icons, indices, and symbols) is useful in bringing order and clarity to the multitudes of phenomena that can be read for meaning. Then, potentially even more useful is his identification of the three components of the signsystem (sign, object, and interpretant). For this can help us understand how any given sign might be deemed "positive." We shall define this central term shortly, but first we can note that, however it is in fact defined, it is possible for this quality to "reside" or "inhere" in the sign, and/or the object, and/or the interpretant. Consider, for instance, the quality of beauty often regarded as positive (as we shall see) - and the question of whether an artwork is beautiful. In that context, one could regard the artwork as a sign (an icon), the painter's state of mind as the object, and the art viewer as the interpretant. According to Wilber (1996), theories of art differ in where they "locate" the beauty of art. Formalist theories locate it in the sign itself, such that an artwork might be inherently and objectively beautiful (e.g., 
Running head: POSITIVE SEMIOTICS

Hanslick, 1986). By contrast, influenced by Romanticism, intentional theories locate it in the object, i.e., in the original intent, feeling, or vision of the creator (e.g., Croce, 1995). Finally, reception and response theories place the onus on the interpretant, whereby beauty is conferred by the viewer (e.g., Passmore (1991, p.34), who wrote that "the interpreter, not the artist, creates the work"). However, Wilber argues that it is possible to regard all these theories as valid, albeit partially so, in that beauty can reside in the artwork itself, and/or in the original intent of the artist, and/or in the response of the viewer.

Thus, a given sign might be appraised as positive based on the sign itself, and/or the object, and/or the interpretant. To begin with, positivity might be "evident" in the sign itself. For instance, a natural "Duchenne" smile is nearly-universally appraised as conveying a positive mental state or intention on the part of the smiler (with some exceptions; Ekman \& Friesen, 1982; Krumhuber \& Manstead, 2009). Conversely, positivity may be there in the object, but not necessarily the sign. To give a personal example, I once visited a religious temple, and sought to express my respect for my hosts and surroundings by clasping my hands behind my back, only to be gently told that this gesture actually conveyed impoliteness and even aggression in this context. Thus, even though the "object" (i.e., mental state and attitude) I wished to signify was positive (e.g., respect), the sign by which I sought to communicate that was appraised by others as negative. This point then brings into play the third factor, in that independently of the sign and the object, any given phenomenon can be appraised as positive by an interpretant. In the case of my temple experience, cultural factors shaped how my body language sign was received: people accustomed to the temple context appraised it as negative, whereas an observer who was not part of that context may have interpreted it differently. In other instances, the role of the interpretant may be even more idiosyncratic and subjective, in that people develop their own unique patterns of association 
Running head: POSITIVE SEMIOTICS

based on life experience (where a given phenomenon may evoke positive thoughts or memories for one person that are not shared by others).

As a final point, one might even suggest that a sign's positivity is a function of its "presence" across the three aspects of the sign-system. That is, a case where positivity is evident or inherent in the sign, and the object, and the interpretant conveys more positivity than cases where it is there in only one or two of the three (as in some of the examples above). For instance, a Duchenne smile would probably satisfy all three, in that it is usually,

(a) an unambiguous sign of positivity, (b) genuinely expresses a positive mental state (although see Krumhuber and Manstead (2009) for contrary evidence), and (c) is almostuniformly interpreted as positive (Soussignan, 2002). We might try to capture this point as a formula, which we might refer to as the "presence" of positivity in a sign-system. (In addition to "presence," two further considerations in relation to the positivity of a sign-system will be introduced below, namely "scale" and "nature.") Thus, if positivity is denoted as Pos, the sign as $\mathrm{Si}$, the object as $\mathrm{Ob}$, and the interpretant as $\mathrm{In}$, we could express this idea as a heuristic equation, such that $\operatorname{Pos}=f(S i+O b+I n)$. Obviously, this is not a "true" mathematical formula, since these are not calculable units, and cannot in any sense be quantified and added. Nevertheless, it might help us to appreciate the dimensions of how a sign might be positive or otherwise. Now we need to ask, what does the qualifier "positive" mean here?

\section{The Positive}

Although the term "positive" has numerous meanings, these essentially take one of two main forms, relating to either, (a) affirmation, or (b) desirability (Pawelski, 2016). The former can imply certainty (e.g., being sure about something) and confirmation (e.g., in relation to tests), whereas the latter implies that something is good or beneficial in some way. The latter is the one we are drawing on here. In that respect, this paper takes inspiration from the field of 
Running head: POSITIVE SEMIOTICS

positive psychology (PP), a branch of academia focused on understanding and facilitating wellbeing. Since its inception, PP has encouraged the creation of other fields that similarly adopt the positive prefix, from "positive education" (Seligman, Ernst, Gillham, Reivich, \& Linkins, 2009) to "positive health" (Seligman, 2008). These new paradigms relate to PP in two main ways. Some cases are a hybrid field, in which a discipline is intermingling with PP, drawing upon theories and practices associated with it. In the case of "positive education," for instance, educators and scholars draw on PP frameworks such as "character strengths" and apply them in an educational context (Park \& Peterson, 2008). In other cases though, fields have not incorporated PP per se, but have simply been inspired or encouraged by PP to develop a more positive orientation within their own context and parameters. This appears to be the case with Seligman's (2008) notion of "positive health," which he suggests merely has "parallels" to PP, in that it focuses on "[physical] health rather than illness" (just as PP focuses on mental health rather than mental illness) (p.3). In the case of this proposed paradigm of PS, both approaches are relevant: there is an interest in how semiotics intersects with PP, since the latter can broadly be defined as "the science and practice of improving wellbeing" (Lomas, Hefferon, \& Ivtzan, 2015, p.1347), and wellbeing is central to the notion of positivity, as we shall see; and also, like PP, are aiming to explore the positive aspects of semiotics more broadly (i.e., in ways that might fall outside the scope and remit of PP). But, again, what does positive mean in this context? We've already suggested that our interest is with the second broad meaning of the term, i.e., desirability.

Of course, desirability is a complex issue. For instance, Pawelski (2016) offers one inclusion criterion and five continuum criteria for identifying something as positive (in the sense of desirability). The inclusion criterion is simply preference, in that a phenomenon is positive if its presence is preferred to its absence. Then, the continuum criteria indicate the "scale" of positivity, with positivity being a function of: (a) relative preference (the strength 
Running head: POSITIVE SEMIOTICS

of the preference for it over something else); (b) sustainability across time (the longer-lasting the better); (c) sustainability across persons (the more popular the better); (d) sustainability across effects (the more positive knock-on effects, the better); and (e) sustainability across structures (the more scalable and transferable across organisational and cultural contexts, the better). This kind of analysis is very useful. In that respect, we can add to our heuristic formula introduced above, namely $P o s=f(S i+O b+I n)$, where the positivity of a sign $(P o s)$ is a function of the extent to which the positivity is present in the sign $(\mathrm{Si})$, and/or object $(O b)$, and/or interpretant $(I n)$. Then, based on Pawelski's analysis of the continuum criteria, it can be argued that positivity is enhanced by the extent to which something is preferred $(P r)$ relative to other phenomena, and is sustained across time $(T i)$, people $(P e)$, effects $(E f)$, and structures $(S t)$. To give an example, imagine two instances of a smile: a polite smile between two passing strangers that is of little import, impacts no-one else, and is forgotten soon after; versus a beaming smile by a politician, offered as a sign of electoral victory to thousands of adoring supporters, promising a prosperous and desired future. The latter would score significantly more strongly in terms of preference and sustainability across time, people, effects and structures. Thus, we might refer to Pawelski's criteria as the "scale" of positivity in a sign-system (to add to the "presence" of positivity discussed above). Together, these considerations create the formula $P o s=f((S i+O b+I n) \times(P r+T i+P e+E f+S t))$.

Moreover, one can go further still, and attempt to elucidate what desirability might actually consist of. To shed light on this issue, consider two intersecting forms of desirability: normative (i.e., widely regarded as desirable), and non-normative (i.e., idiosyncratic, personal desires). Both are relevant to PS. Beginning with normative desirability, there are many ways of thinking about this notion. One particularly useful lens is the conceptual triad of goodness, truth, and beauty (Martin, 2016). This schema has a long, auspicious, and moreover crosscultural pedigree, from its association with Plato in the West (who wrote in Phaedrus of "the 
Running head: POSITIVE SEMIOTICS

ability of the soul to soar up to heaven to behold beauty, wisdom, goodness"), to its appearance in the Bhagavad Gita in the East (with its valorisation of "words which are good and beautiful and true"). It has continued to inspire thinkers down the centuries, from Diderot (who in 1776 compared le vrai, le bon, et le beau - the true, the good, and the beautiful - to the trinity of Father, Son, and Holy Spirit), to Kant (whose Critiques of Pure Reason, Practical Reason, and Judgement, dealt respectively with issues of truth, goodness and beauty). Although the power of this triumvirate has been challenged by modern philosophies - such as the notion of truth being contested by post-modern relativism - scholars like Gardner (2011) have emphasised that they are still salvageable and relevant.

Drawing on this schema, we can begin to outline some heuristic principles that may help us assess the extent to which a sign is positive. Taking goodness first, in this context of semiotics, we might say this means that a sign-system points towards the enactment of some moral quality or code (recognising of course that are disagreements about what constitutes such a quality or code). Given a moral code that valorises acts of charity, for instance, then a sign-system that signifies an act of charity could be deemed good. But goodness is arguably neither necessary nor sufficient to render a sign-system positive. First, it is not necessary, in that so long as a sign-system is not explicitly antithetical to goodness - i.e., merely neutral with respect to morality, being amoral rather than immoral - it could just be true and beautiful and thus be deemed positive. And goodness is arguably not sufficient, since in combination with the antithesis of truth (i.e., falsity) it is undermined.

To appreciate this latter point, consider the second quality, truth. In the context of semiotics, this essentially means representational accuracy, i.e., a sign really does signify what it purports to signify (all three elements of the sign-system are aligned and coherent). In that sense, in most cases, truth is necessary but not sufficient for rendering a sign positive. It is necessary, in that its absence would usually undermine any other quality the sign possesses. 
Running head: POSITIVE SEMIOTICS

A sign that appeared to signify charity would be ostensibly good, but if it was false (e.g., someone faking generosity), it would be rendered meaningless. There are some caveats though, in that one could imagine situations in which a lie served sufficiently good, moral ends that the normative commitment to truth is suspended. Generally, though, signs must surely be truthful to be positive. But truth is not sufficient, in the absence of goodness or beauty. A sign that conveys hatred, for instance, may truly reflect its author's mental state, but this lacks goodness, and so could not be deemed positive. Finally, beauty pertains to the aesthetic qualities of the sign-system; this quality is neither necessary nor sufficient to make a sign positive. But it does help strengthen its positivity. In that sense, the more boxes a sign ticks (e.g., good, true, and beautiful), and the more strongly it does so, the more positive we might consider it to be; we'll return to his point shortly.

In addition to these normative desirability concerns, we also need to consider nonnormative concerns, i.e., personal, idiosyncratic wants and preferences. That is, aside from normative considerations, a sign can be positive if it signifies something that a person desires. Obviously, such signs are inherently subjective, and attain their meaning relative to a person's individual context: a dark cloud signifying impending rain, for instance, will elicit very different reactions from a couple on their wedding morning and a farmer who has suffered months of drought. That said, such sign-systems are not divorced from concerns of goodness, truth, and beauty. The criterion of truth still applies, in that a sign that did not really signify what it purported to could not be deemed positive in an ultimate sense (e.g., if the farmer was mistaken about the raincloud signifying rain). So too does the criterion of goodness. After all, a sadist might desire a sign that some other person is in pain, which could not be regarded as positive. However, is it still worth adding this non-normative, personal criterion into the mix. That is, it was suggested above that more boxes a sign ticks (e.g., good, true, and beautiful), and the more strongly it does so, the more positive it is. Personal 
Running head: POSITIVE SEMIOTICS

desirability is then an additional box: a sign may be good, true, and beautiful, and then if in addition it is truly personally desired by someone, its positivity only increases further.

In that respect, we can add to our heuristic formula introduced above. It was argued that the positivity of a sign $(P O S)$ is a function of its" "presence" - i.e., the extent to which the positivity is present in the sign $(\mathrm{Si})$, object $(\mathrm{Ob})$, and interpretant $(\mathrm{In})$ - and also its "scale," i.e., the extent to which something is preferred $(P r)$ relative to other phenomena, and is sustained across time $(T i)$, people $(P e)$, effects $(E f)$, and structures $(S t)$. In addition to these considerations, it was suggested that positivity consists in goodness $(G o)$, truth $(\operatorname{Tr})$, beauty $(B e)$, and personal wants $(W a)$. We might refer to this as the "nature" of the positivity in the sign-system. Together, these considerations create the overarching formula $\mathrm{Pos}=f((\mathrm{Si}+\mathrm{Ob}$ $+I n) \mathrm{x}(P r+T i+P e+E f+S t) \times(G o+T r+B e+W a))$. This formulation is presented in a slightly different way in table 1 below

[insert table 1 here]

Again, it bears repeating that this is not a "true" formula, since these are not calculable units, and cannot in any sense be quantified and added. Nevertheless, it helps us to appreciate the ways in which a sign might be positive or otherwise. It will be worth bearing this in mind as we consider what PS might actually pertain to, with the sections below outlining various manifestations of PS, together with a consideration of relevant literature.

\section{Semiotic Channels}

To provide substance to the notion of PS, and to explore what it might mean in practice, the remainder of the paper will explore four prominent semiotic channels (i.e., types of signsystem). In each case, we will consider what might constitute PS in that channel. The channels below are: non-exhaustive (in that PS is not necessarily limited to those below); overlapping (in that a given communicative act may touch upon more than one channel); and granular (in that each can be differentiated further into sub-channels). Nevertheless, touching 
Running head: POSITIVE SEMIOTICS

upon these four can at least provide an entry into the notion of PS, and hopefully stimulate further research and enquiry into these areas. The channels in question are: discursive language; body language; symbols; and art. To reiterate, these four do not exhaust the potential semiotic channels that exist; indeed, as argued at the start, it is possible to view everything as a "text" that can be read for meaning, from DNA structures to weather patterns. Nevertheless, they will suffice here to provide an initial sense of the scope and nature of PS.

\section{Discursive language}

The first two channels focus on language, which we can usefully subdivide into (a) discursive language (i.e., using spoken or written words), and (b) body language (i.e., bodily gestures and expressions, including the special case of sign language). In real life, these channels are often combined in one communicative act, but conceptually it is possible and helpful to differentiate them. Thus, this first channel encompasses the vast terrain that is discursive language, which essentially means spoken or written words. This is obviously a huge area. Indeed, people could easily assume that this channel constitutes semiotics in its entirety; that is, if semiotics rests upon the idea that phenomena are "texts" that can be "read for meaning", then common sense might alight upon what are conventionally viewed as texts, i.e., sequences of words. However, a key point of this paper is to draw attention to other semiotic channels, which can often be overlooked. That said, it would be remiss if we did not also consider this central semiotic phenomenon of discursive language, if only briefly. To reiterate, this basically means words, either individually (i.e., distinct lexemes), or in sequence (in that an entire sentence of words could be treated as a sign). But what does PS mean in this context?

It is perhaps easier and more common to conceptualise this question as a negative, i.e., in terms of avoiding communications that are explicitly negative. Two of the main proscriptions in that respect are injunctions against falsehoods and hate speech. The former is 
Running head: POSITIVE SEMIOTICS

a cornerstone of most legal systems, for instance. Following the formula above, it could be deemed negative in that it violates the commitment to truth embodied in our positivity equation. The latter - defined by the Cambridge English Dictionary as "public speech that expresses hate or encourages violence towards a person based on something such as race, religion, sex, or sexual orientation" - is similarly proscribed within the legal system. It could be considered negative in abrogating the ideal of goodness, not to mention - from the perspective of its target - those of beauty and desirability, and likely also truth too.

It is also intriguing to consider the notion of PS in the positive. The antithesis of uttering falsehoods is obviously a commitment to truth. But can we go further and also identify the antithesis of hate speech - "love speech" perhaps. An interesting example in that respect can be found in Buddhism, with its ethical precept of "right speech" (samma vaca). In Buddhist teachings, this precept is described both in negative and positive terms. The former essentially means refraining from the twin misdeeds, outlined above, of false and hate speech. As outlined in the Pali canon (SN. 45.8), this involves "Abstaining from lying, from divisive speech, from abusive speech, and from idle chatter." But the teachings go further, outlining a vision of communication that is explicitly positive, with five main guidelines (AN 5.198), namely: "It is spoken at the right time. It is spoken in truth. It is spoken affectionately. It is spoken affectionately. It is spoken with a mind of good-will." Clearly, this goes beyond simply not lying or being hateful, but outlines a more ambitious vision of how discourse can be positive, wherein one is minded to convey one's message in a way that will be optimal for those receiving it. Here one could imagine an ideal wherein their speech ticks all the "boxes" of positivity outlined in the formula above, i.e., (a) has the "presence" of positivity inhering in all aspects of the sign-system (sign, object, and interpretant); (b) per Pawelski's (2016) continuum criteria, has significant scale, being greatly preferred relative to other phenomena, 
Running head: POSITIVE SEMIOTICS

and is sustained across time, people, effects, and structures; and (c) meets all the "nature" criteria of positivity (goodness, truth, beauty, and desirability).

On that point though, one is also reminded that such speech can still challenge its listeners (and so perhaps lacks desirability from their present perspective). A parent might admonish their child for misbehaviour, for instance, in way that follows these principles, and has the child's best interests at heart, and yet is unappreciated by the child. In that respect, Aristotle's line about skilfully expressing anger comes to mind: "to be angry with the right person and to the right degree and at the right time and for the right purpose, and in the right way - that is not within everybody's power and is not easy." Clearly, this is a complex area about which much could be said. It is beyond the scope here to delve into all the nuances of what PS might consist of in relation to discursive language. Rather the point of this paper is simply to outline the main territory of PS, with the aim of generating a fruitful programme of enquiry into its dynamics. As such, we are merely briefly touching upon some of the key areas, the next of which is body language.

\section{Body Language}

Moving beyond discursive language, we can begin to appreciate the point made above that all phenomena can be "read for meaning," and consequently pertain to PS. In that respect, the second main channel considered is body language. This itself can be refracted into various forms, including facial expressions, gestures, and sign language, which we'll briefly touch upon in turn.

Facial expressions have been studied intensely by scholars such as Ekman (2009), with his work on micro-expressions. Much could be said on this topic in relation to PS, but we can by way of example just focus on the aforementioned phenomenon of the "Duchenne" smile, whereby the coordination of multiple muscle movements (including the mouth and the eyes) combine to reflect a positive (i.e., happy) internal mental state. As noted above, in this 
Running head: POSITIVE SEMIOTICS

case, positivity might be deemed to inhere in all three components of the sign system, in that it is usually, (a) an unambiguous sign of positivity, (b) genuinely expresses a positive mental state, and (c) is uniformly interpreted as positive (Soussignan, 2002). However, we might delve further into the nuances of PS by noting that these points may not always apply. For instance, with respect to (b), research by Krumhuber and Manstead (2009) suggests it may be possible to voluntarily feign this type of smile. Or regarding (c), we can note that a sign is always a sign for someone. In that sense, one can imagine scenarios in which even though the smile genuinely reflects a positive mental state in the person smiling (the sign and object are consonant), it is yet not perceived as positive by the interpretant. Imagine a football supporter smiling because his team has beaten a rival team. A fellow fan will perceive this as positive, mainly in relation to the desirability criterion - i.e., the smile reflects a state of affairs (satisfaction at one's team winning) that is both desired and welcomed - whereas a rival supporter will not. In that respect, here we might also point to Pawelski’s (2016) continuum criteria, in that the positivity is only sustained across a limited set of people and structures that particular football club and its in-group of supporters - and not to those outside. Such examples highlight the complexities of reading signs (such as smiles) for meaning and interpreting their significance.

A related phenomenon to facial expression is that of gestures (i.e., communicative acts using the body). As with all other channels and sub-channels here, this is a fertile area of enquiry, one which has been much studied across diverse academic disciplines. These range from cognitive psychology (e.g., where scholars have analysed how gestures communicate information about one's mental state) (Hostetter \& Alibali, 2008), to ethnography (e.g., where socially-learned gestures have the power to demarcate in-group from out-group) (Herzfeld, 2009). Regarding PS, there has already been a fair amount of research on gestures perceived as positive, and moreover the contexts in which this occurs (which, in some cases, 
Running head: POSITIVE SEMIOTICS

can differ markedly across cultures and time-periods). Some gestures appear to have greater cross-cultural universality, with less scope for idiosyncratic meanings and interpretations, and potentially even intuitive or instinctual origins. One example might be the gentle stroking of another's skin, which is not only perceived as an act of caring and/or friendship across human cultures, but among non-human animals too (such as primates), lending credence to the notion that it is instinctual and biologically-driven (Boccia, 1983). Conversely, other gestures - such as the thumbs-up sign - are more culturally specific and contingent, and the product of social trends in specific places and eras (Sherzer, 1991).

Finally, in considering the semiotic power of gesture, special mention must go to the various sign languages which have been developed across the world. These generally involve signs made by moving the hands, together with facial expressions and bodily postures (Stokoe, 2005). (For instance, a question can be indicated by the signer raising their eyebrows, widening their eyes, and tilting their bodies forward.) In fact, such is the power of articulation facilitated by such modes of communication that these are essentially discursive languages - albeit ones performed with the body - and so could equally be situated in the section above. Thus, the points made there apply equally here. Nevertheless, it is worth mentioning sign languages on their own terms here, if only because they reveal the richness of semiotic channels that do not require vocalised or written language. And, from the perspective of PS, it can be noted that some signed gestures can have particularly profound or emotive meanings, which moreover may be amplified by the way such signs incorporate the signer's embodied being (in a way that spoken language does not); for instance, in American Sign Language, terms such as "love" and "feel" are signed around the location of the chest (and previously the heart specifically) (Frishberg, 1975). 
Running head: POSITIVE SEMIOTICS

\section{Symbols}

The third main semiotic channel we shall consider here is the deeply rich world of symbols. Recall above that, for Peirce (1982), symbols were one of three types of sign (alongside icons and indices), being ones whose relation to their objects is of an "imputed character" (i.e., according to convention or social agreement). However, we also noted that differentiating between the types of sign can be difficult in practice, as a sign may in fact be a combination of multiple types. Thus, as we shall see, it is possible to find symbols that also share the quality of being icons and/or indices. As with the other channels here, we can elucidate this category by touching upon several sub-channels, including logos, emoticons, and valuesignifiers.

The term "logo" is used here as an all-encompassing label for the vast collection of graphic images designed or adopted by people to represent phenomena of significance. Such phenomena include organisations of all forms, from religions (e.g., Christianity represented by the cross), to companies (e.g., Nike represented by the swoosh), to regions (e.g., nations represented by national flags). They also include natural and behavioural phenomena, from biological entities and processes (e.g., elements represented in the periodic table) to human actions (e.g., proscriptions against behaviours like the no-smoking sign). They further encompass more abstract ideas, relating to endeavours from medicine (e.g., the caduceus as a symbol of healing) to philosophy (e.g., yin-yang as a dialectical symbol of the insights of Taoism). The wealth of such symbols is so vast that it rivals discursive speech for richness, fecundity, and complexity (Cirlot, 2006), so clearly we cannot here go beyond the briefest of summaries. But in the context of PS, one point is particularly worth emphasising, namely the complexity of symbols in determining their meaning (positive or otherwise). Take the Christian cross for instance. On a literal level it is most closely associated with the suffering of Christ, which would be judged as negative in all elements of the sign-system; yet it is also 
Running head: POSITIVE SEMIOTICS

valued as a sign of hope and redemption, even amidst that suffering, and so in its deeper levels contains a message that is deeply profound in its positivity to many people. But then, even granting that, many non-Christians may be unmoved by the symbol, or even repelled by it (e.g., if they have suffered in relation to Christianity) (Boys, 1994). Such is the complexity of symbols (and indeed many signs) that appraising them vis-à-vis positivity is a remarkably complex task in practice (and one which is also contingent and influenced by context).

A second type of symbol worth mentioning is the emergent language of emoticons pictorial icons (in Peirce's terminology) which represent facial expressions in some way (from the imaginative use of punctuation to more "realistic" facial depictions). In one sense these could also just be regarded as a species of logo. However, whereas logos tend to be individual stand-alone graphics (although they can also be conceptually or historically linked together), emoticons are a form of structurally-associated discourse unto themselves. That is, like other semiotic channels (such as discursive language), emoticons facilitate a range of expressions and communicative intent. But they are also worth mentioning specifically as a good example of the spontaneity and generativity of semiotic systems. For they represent a form of communication which did not functionally exist until recently - although forerunners have been identified in English texts dating back to at least the $19^{\text {th }}$ Century - having been formally proposed and used in the 1980s, and since rapidly gaining near ubiquity over the past decade (Houston, 2014). As with all the types of signs considered here, much could be said about emoticons from a PS perspective. But one consideration seems especially salient, namely what might be called the "flattening" of affect. It has been suggested that, compared to other semiotic channels - from discursive language to logos - emoticons are particularly poor at conveying subtlety, depth, and intensity (Biocca \& Levy, 2013). Thus, regarding the "scale" of the sign's positivity - derived from Pawelski's (2016) continuum criteria emoticons perhaps are relatively limited in the extent to which positivity is sustained across 
Running head: POSITIVE SEMIOTICS

time, people, effects, and structures. A smiley face is rigidly the same, allowing minimal differentiation, and lacking other cues that could help refine its meaning. The impact of such communications trends upon wellbeing and relationship dynamics are thus worthy of further study.

A third type of symbol worth touching upon here are what might be called valuesignifiers. These are not distinct logos (i.e., recognisable graphics), but rather the almost infinitely rich and complex array of signs that can be interpreted as providing information about people's values, ideals, worth, and so on. These include the clothes people wear, the belongings they buy and display, the money they earn, and so on. All these phenomena "say something" about a person, and moreover may often be consciously chosen for that very reason, e.g., as a way of constructing and communicating one's identity (see e.g., Thomsen and Sørensen (2006) on parental choices of pram in that regard). An expensive suit, for instance, might communicate an array of messages, including a certain wealth and status, a conventional and well-rewarded occupation, materialist values, and a commitment to being well-groomed. None of those need necessarily be actually true of the wearer (they may usually disdain such attire but are attending a wedding, perhaps), but absent other cues are liable to be read that way. For people are very attuned to such signs, and make inferences based on them (e.g., about a person's social status). In that respect, from a PS perspective, a key concern is that status is a "valuable resource" (Huberman, Loch, \& Önçüler, 2004), and disparities in relative status can be detrimental to the wellbeing of the worse off, and sometimes even for the better-off too (e.g., through reduced social capital in their shared society) (Wilkinson \& Pickett, 2010). As such, while displays of worth may be positive for the wearer (e.g., a sign of their affluence), it may not be for other interpretants, thus highlighting the complexities around interpreting the nature of signs (e.g., the extent of their 
Running head: POSITIVE SEMIOTICS

positivity). Signs can thus be "fractured" - subject to diverse and even conflicting meanings as we have seen above (such as in relation to logos).

\section{Art}

The final semiotic channel we shall consider here is that of art. This of course overlaps with the channels considered above, since art can incorporate discursive language (e.g., literature, or song lyrics), body language (e.g., dance, or sculpture), and symbols (e.g., in paintings, or jewellery). However, it is also worth considering on its own terms, since art can generate and convey meaning in ways that do not necessarily involve these other channels. To illustrate this point, we'll briefly consider three prominent artistic modalities: architecture, painting, and music.

With architecture, the way in which buildings and environments are constructed is full of meaning, both in terms of what those implementing it (commissioner, designer, builder, etc.) intended to convey, and how it is perceived by its audience and users. Such meaning can be conveyed in various ways. Much may be said, for instance, by the choice of building styles and materials, particularly in the (post)-modern age (when all styles and materials are available to select from). For instance, neoclassical architecture - a movement initiated in the $18^{\text {th }}$ century - revives the style of the classical world, characterised by grandeur of scale, simplicity of geometric forms, and dramatic use of columns. Its contemporary use thus communicates something about the ideals to which its implementors aspire, especially when invoked in reaction to other architectural trends, such as modernism - with neoclassicalism sometimes referred to as anti-modernism - which in turn communicate their own values and ideals (Brumfield, 1989). Meaning can also be conveyed through choices around shape and dimensions. An interesting example is the use - especially in classical and neoclassical architecture - of the "golden ratio" (even if there are popular misconceptions about how widespread or deliberate its use is; Markowsky, 1992). It occurs whenever the irrational 
Running head: POSITIVE SEMIOTICS

number $\Phi$ (roughly 1.618, rounded down) describes both the ratio between two quantities and the ratio between the larger quantity and the sum of the two. This would occur, for instance, with a building that is 5 metres high and 3.09 meters wide (where you get 1.618 if you divide the height by the width, and if you divide the height plus the width by the height). The golden ratio is widely regarded as especially aesthetically pleasing, for reasons that are much debated, including the possibility that it reflects patterns that recur widely in nature (e.g., structuring spiral-like configurations such as seashells and galaxies) (Green, 1995). In that sense, its deployment in architecture can be seen as having a positive semiotic function, namely in that it signifies - in some subtle and perhaps mysterious and poorly-understood way - an intrinsic quality of beauty, and relatedly, possibly also the other elements of the "nature" aspect of the sign-system, such as goodness and truth.

This point brings us to the second artistic channel considered here, namely painting. For numerous paintings have been analysed as being structured according to the dimensions of the golden ratio, with this purportedly helping to account for the aesthetic qualities of the work (with Botticelli's “The Birth of Venus” often cited as an example) (Cellucci, 2015). Thus, as with architecture, beauty may be conveyed in paintings through the deployment of the golden ratio, and by other qualities that in the natural world are also interpreted as being positive in some way - such as symmetry in faces, which research has suggested may be indicative of health in people, and relatedly is typically perceived as attractive (Fink, Neave, Manning, \& Grammer, 2006). However, that being said, we must be wary of universalising aesthetic judgements, both across time and cultures. Standards and conventions of beauty in art can change - often radically - both within cultures across time (e.g., in terms of the development of new artistic traditions), and across cultures. With respect to the latter, for instance, an interesting counterpoint to much of Western art is that of Zen aesthetics. Many Western artistic trends - especially before the $20^{\text {th }}$ Century - are characterised by a degree of 
Running head: POSITIVE SEMIOTICS

realism (e.g., literal representational accuracy), vivid use of colour, harmonic proportion, and a full composition (i.e., paint covering the entire canvas). By contrast, Zen art is often guided by other qualities which reflect the philosophy of Zen itself, and relatedly the way of being it seeks to encourage (Lomas, Etcoff, Gordon, \& Shonin, 2017). These include Japanese concepts such as kanso (elegant simplicity), fukinsei (asymmetry, irregularity), koko (austere sublimity), shizen (naturalness), datsuzoku (freedom from convention), seijaku (stillness, tranquillity), and yūgen (profound depth) (Hisamatsu, 1971). In Zen then, to the extent that an artwork can convey these meanings and qualities, it will be appraised as positive (e.g., deemed good, true, and beautiful). Likewise, in terms of Pawelski's (2016) continuum criteria, the "scale" of the sign's positivity is reflected in the degree to which these qualities are preferred to other possible aesthetic considerations, and the extent to which their effects are sustained across time, people, effects, and structures.

The final artistic channel we'll touch upon here is music. As with the other channels, considerable work has gone into exploring what Antović (2009) calls "musical semantics," i.e., how music conveys or elicits meaning, and more generally signifies certain qualities. There are of course different perspectives on this issue. For instance, Antović suggests that $20^{\text {th }}$ century music theory oscillated between two main stances: "formalist" (whereby music has no other meaning "than itself," i.e., as a self-contained system), and "referentialist" (whereby music evokes other phenomena, such as sounds in nature). However, most theorists agree that music can be read for meaning - such as the emotions it conveys or evokes - even if there are differences of interpretation at the granular level. Swain (1997) for instance cites the example of Beethoven's Appassionata; he suggests that most people would assent that it connotes "explosive fury" rather than "peaceful contemplation," a judgement made on the basis of factors such as tempo, volume, and harmonic regularity; however differentiating explosive fury from "passionate determination" would be trickier. Other musical factors 
Running head: POSITIVE SEMIOTICS

influencing interpretation include chords and melody. Perhaps the most obvious example is the distinction between major and minor keys, which tend to be associated with - and to elicit - positive and negative emotionality respectively (for reasons which are much researched and debated) (Koelsch \& Siebel, 2005). However, the picture is more complicated than simply saying that major keys are constitutive of PS, since a considerable literature exists on why people derive meaning, value, and even pleasure from ostensibly sad music (Sachs, Damasio, $\&$ Habibi, 2015). Furthermore, as with the other artistic modalities, there are considerable cross-cultural differences - although also universals - in terms of how music is perceived and interpreted, as well as in styles and traditions that are popular and perceived as being of high quality (Laukka, Eerola, Thingujam, Yamasaki, \& Beller, 2013).

\section{Conclusion}

This paper has sought to introduce and substantiate the notion of PS. This is proposed as a label for disparate research and theorising that is already underway across various academic fields, from psychology to anthropology. The paper began by drawing on Peirce's (1998) theory of semiotics, suggesting that a sign's positivity is a function of its "presence" in the sign-system, namely the extent to which it inheres in its three aspects. Thus, where positivity is evident or inherent in the sign, and the object, and the interpretant - such as a Duchenne smile (albeit possibly not always) - this conveys more positivity than cases where it is there in only one or two of the three. This suggestion was captured in a formula (albeit not a "true" mathematical one, with calculable units), where if positivity is denoted as Pos, the sign as $\mathrm{Si}$, the object as $O b$, and the interpretant as $I n$, we could express this idea as a heuristic equation, such that $P o s=f(S i+O b+I n)$. We then delved into the notion of what "positive" might mean in the context of PS, focusing on the notion of desirability, following Pawelski's (2016) analysis. Based upon his continuum criteria, it was suggested that a "scale" of positivity may be identified, with positivity being a function of the extent to which something is preferred 
Running head: POSITIVE SEMIOTICS

$(\mathrm{Pr})$ relative to other phenomena, and is sustained across time $(T i)$, people $(\mathrm{Pe})$, effects $(\mathrm{Ef})$, and structures (St). Finally, we looked specifically at the "nature" of desirability, i.e., what it might consist of in practice, differentiating between normative and non-normative forms (both of which are relevant to PS). The former was elucidated using the conceptual triad of goodness $(G o)$, truth $(T r)$, and beauty $(B e)$, whereas the latter was characterised as personal wants $(W e)$. Thus, overall, the positivity of a sign is a depends upon its presence, scale, and nature. Together, these considerations, and their components, can be expressed using the following heuristic formula: $P o s=f((S i+O b+I n) \times(P r+T i+P e+E f+S t) \times(G o+T r+$ $B e+W a))$.

Having then clarified the notion of PS, the remainder of the article then looked at four main semiotic channels, each of which comprise various subchannels, and each of which interrelate and overlap. These included: discursive language; body language (including facial expressions, gestures, and sign language); symbols (including logos, emoticons, and valuesignifiers); and art (including architecture, painting, and music). Throughout these sections, illustrative research and theorising was cited to flesh out the idea of what PS might look like in the context of that particular channel and subchannel. However, the relevant literature is vast, and so it was beyond the scope of this paper to touch on more than an indicative fraction of this. The point of the paper was simply to shine a light on what is and can be a fruitful area of academic enquiry - i.e., the way in which sign-systems are or could be positive - and to allude to the disparate work that already exists in relation to this. Relatedly, the paper has hopefully also indicated generative avenues for further research in this area. This could include, for instance, analysing communication dynamics across these semiotic channels and others, since the list above is non-exhaustive - through the prism of the formula above. More generally, such research could also include studying cross-cultural differences in how sign-systems are created, perceived, and interpreted, and more generally, the impact of all 
Running head: POSITIVE SEMIOTICS

forms of context upon how signs are read for meaning. Clearly, much more work can be done to further our understanding of this important topic, and hopefully this paper can stimulate further efforts in that regard.

More broadly, it is hoped that this paper can help foster a rapprochement between psychology and semiotics, helping promote a mutually beneficial process of dialogue and collaboration. As noted at the start, despite their common origins, these fields of enquiry have subsequently largely followed independent and even antagonistic paths. However, as the likes of Bouissac (1998) have argued, there is much to gain from establishing a closer relationship and pursuing research and theorising at their intersection. This does not merely mean with respect to wellbeing - the focus of this present paper, with its emphasis on PS - but in all aspects of human functioning. Just to give one prominent example, there is intense interest in psychology - and related fields, from neuroscience to social policy - of the impact upon mind and behaviour of new patterns of communication fostered by the emergent technologies and practices of social media (Best, Manktelow, \& Taylor, 2014). These range from the adoption and effect of new modes of communication, such as emoticons (Biocca \& Levy, 2013), to people's (in)ability to perceive and interpret so-called "fake news" and other forms of media manipulation (Balmas, 2014). To fully understand such phenomena it is imperative to bring both psychology and semiotics into consideration, and for scholars from these two fields (and others) to collaborate in exploring their intersection. It is hoped that this paper offers an example of such an exploration that will be useful and generative over the years ahead. 
Running head: POSITIVE SEMIOTICS

\section{References}

Antović, M. (2009). Towards the semantics of music: The twentieth century. Language \& History, 52(1), 119-129.

Balmas, M. (2014). When fake news becomes real: Combined exposure to multiple news sources and political attitudes of inefficacy, alienation, and cynicism. Communication Research, 41(3), 430-454. doi: 10.1177/0093650212453600

Barthes, R. (1982). Empire of Signs (R. Howard, Trans.). New York: Hill and Wang.

Baudrillard, J. (1972). For a Critique of the Political Economy of the Sign St. Louis, MO: Telos.

Best, P., Manktelow, R., \& Taylor, B. (2014). Online communication, social media and adolescent wellbeing: A systematic narrative review. Children and Youth Services Review, 41, 27-36. doi: 10.1016/j.childyouth.2014.03.001

Biocca, F., \& Levy, M. R. (2013). Communication in the age of virtual reality. New York: Routledge.

Boccia, M. L. (1983). A functional analysis of social grooming patterns through direct comparison with self-grooming in rhesus monkeys. International Journal of Primatology, 4(4), 399-418.

Bouissac, P. (1998). Converging parallels: Semiotics and psychology in evolutionary perspective. Theory \& Psychology, 8(6), 731-753. doi: 10.1177/0959354398086002

Boys, M. C. (1994). The cross: Should a symbol betrayed be reclaimed? CrossCurrents, 527.

Brumfield, W. C. (1989). Anti-modernism and the neoclassical revival in Russian architecture, 1906-1916. Journal of the Society of Architectural Historians, 48(4), $371-386$. 
Running head: POSITIVE SEMIOTICS

Cellucci, C. (2015). Mathematical beauty, understanding, and discovery. Foundations of Science, 20(4), 339-355.

Chandler, D. (2017). Semiotics: The basics. London: Routledge.

Cirlot, J. (2006). Dictionary of Symbols. New York: Routledge.

Cornejo, C. (2004). Who says what the words say?: The problem of linguistic meaning in psychology. Theory \& Psychology, 14(1), 5-28. doi: 10.1177/0959354304040196

Croce, B. (1995). Guide to aesthetics. Cambridge: Hackett Publishing.

Derrida, J. (1987). Of Grammatology (G. C. Spivak, Trans.). Baltimore: Johns Hopkins University Press.

De Saussure, F. (1916). Course in General Linguistics. New York: Philosophical Library.

Eco, U. (1976). A Theory of Semiotics. Bloomington, IN: Indiana University Press.

Ekman, P. (2009). Lie catching and microexpressions. In c. Martin (Ed.), The philosophy of deception (pp. 118-133). Oxford: Oxford University Press.

Ekman, P., \& Friesen, W. V. (1982). Felt, false, and miserable smiles. Journal of Nonverbal Behavior, 6(4), 238-252.

Fink, B., Neave, N., Manning, J. T., \& Grammer, K. (2006). Facial symmetry and judgements of attractiveness, health and personality. Personality and Individual Differences, 41(3), 491-499. doi: 10.1016/j.paid.2006.01.017

Frishberg, N. (1975). Arbitrariness and iconicity: Historical change in American Sign Language. Language, 696-719.

Gardner, H. (2011). Truth, beauty, and goodness reframed: Educating for the virtues in the age of truthiness and twitter: Basic Books (AZ).

Green, C. D. (1995). All that glitters: A review of psychological research on the aesthetics of the golden section. Perception, 24(8), 937-968. 
Running head: POSITIVE SEMIOTICS

Hanslick, E. (1986). On the musically beautiful: A contribution towards the revision of the aesthetics of music. Cambridge: Hackett Publishing.

Hendricks, G. P. (2016). Deconstruction the end of writing: 'Everything is a text, there is nothing outside context'. Verbum et Ecclesia, 37(1), 1-9.

Hervey, S. (2016). Semiotic Perspectives. London: Routledge.

Herzfeld, M. (2009). The cultural politics of gesture: reflections on the embodiment of ethnographic practice. Ethnography, 10(2), 131-152.

Hisamatsu, S. (1971). Zen and the Fine Arts (G. Tokiwa, Trans.). New York: Kodansha International.

Hostetter, A. B., \& Alibali, M. W. (2008). Visible embodiment: Gestures as simulated action. Psychonomic Bulletin \& Review, 15(3), 495-514.

Houston, K. (2014). Smile! A History of Emoticons. Wall Street Journal, 27 September 2014. http://online.wsj.com/news/articles/SB10001424052702304213904579093661814158 $\underline{946 .}$.

Huberman, B. A., Loch, C. H., \& Önçüler, A. (2004). Status as a valued resource. Social Psychology Quarterly, 67(1), 103-114.

Koelsch, S., \& Siebel, W. A. (2005). Towards a neural basis of music perception. Trends in Cognitive Sciences, 9(12), 578-584. doi: https://doi.org/10.1016/j.tics.2005.10.001

Krumhuber, E. G., \& Manstead, A. S. (2009). Can Duchenne smiles be feigned? New evidence on felt and false smiles. Emotion, 9(6), 807-820. doi: 10.1037/a0017844

Laukka, P., Eerola, T., Thingujam, N. S., Yamasaki, T., \& Beller, G. (2013). Universal and culture-specific factors in the recognition and performance of musical affect expressions. Emotion, 13(3), 434-449.

Langer, S. K. (1953). Feeling and Form: A Theory of Art. New York: Scribner's. 
Running head: POSITIVE SEMIOTICS

Lomas, T., Etcoff, N., Gordon, W. V., \& Shonin, E. (2017). Zen and the art of living mindfully: The health-enhancing potential of Zen aesthetics. Journal of Religion and Health, 56(5), 1720-1739. doi: 10.1007/s10943-017-0446-5

Lomas, T., Hefferon, K., \& Ivtzan, I. (2015). The LIFE model: A meta-theoretical conceptual map for applied positive psychology. Journal of Happiness Studies, 16(5), 1347-1364. doi: 10.1007/s10902-014-9563-y

Markowsky, G. (1992). Misconceptions about the golden ratio. The College Mathematics Journal, 23(1), 2-19.

Martin, J. L. (2016). The Birth of the True, The Good, and The Beautiful: Toward an Investigation of the Structures of Social Thought Reconstructing Social Theory, History and Practice (pp. 3-56): Emerald Group Publishing Limited.

Morris, C. W. (1938). Foundations of the Theory of Signs. Chicago: University of Chicago Press.

Ogden, C. K., \& Richards, I. A. (1923). The Meaning of Meaning. New York: Harcourt Brace.

Park, N., \& Peterson, C. (2008). Positive psychology and character strengths: Application to strengths-based school counseling. Professional School Counseling, 12(2), 85-92.

Passmore, J. (1991). LaSalle, IL: Open Court.

Pawelski, J. O. (2016). Defining the 'positive' in positive psychology: Part II. A normative analysis. The Journal of Positive Psychology, 11(4), 357-365. doi:

$10.1080 / 17439760.2015 .1137628$

Peirce, C. S. (1955). Philosophical Writings of Peirce (J. Buchler Ed.). Dover Publications: Dover Publications.

Peirce, C. S. (1982). The Writings of Charles S. Peirce: A Chronological Edition (Vol. 2). Bloomington I.N.: Indiana University Press. 
Running head: POSITIVE SEMIOTICS

Peirce, C. S. (1998). The Essential Peirce (Vol. 2). Bloomington I.N.: Indiana University Press.

Reybrouck, M. (2004). Music cognition, semiotics and the experience of time:

Ontosemantical and epistemological claims. Journal of New Music Research, 33(4), 411-428.

Sachs, M. E., Damasio, A., \& Habibi, A. (2015). The pleasures of sad music: A systematic review. Frontiers in Human Neuroscience, 9, 404. doi: 10.3389/fnhum.2015.00404

Seligman, M. E. P. (2008). Positive health. Applied Psychology, 57, 3-18. doi: $10.1111 / \mathrm{j} .1464-0597.2008 .00351 . \mathrm{x}$

Seligman, M. E. P., \& Csikszentmihalyi, M. (2000). Positive psychology: An introduction. American Psychologist, 55(1), 5-14. doi: 10.1037/0003-066X.55.1.5

Seligman, M. E. P., Ernst, R. M., Gillham, J., Reivich, K., \& Linkins, M. (2009). Positive education: Positive psychology and classroom interventions. Oxford Review of Education, 35(3), 293-311. doi: 10.1080/03054980902934563

Sherzer, J. (1991). The Brazilian Thumbs-Up Gesture. Journal of Linguistic Anthropology, 1(2), 189-197.

Soussignan, R. (2002). Duchenne smile, emotional experience, and autonomic reactivity: A test of the facial feedback hypothesis. Emotion, 2(1), 52-74. doi: 10.1037/15283542.2 .1 .52

Stokoe Jr, W. C. (2005). Sign language structure: An outline of the visual communication systems of the American deaf. Journal of deaf studies and deaf education, 10(1), 337.

Swain, J. (1997). Musical Languages. New York: W.W. Norton and Company. 
Running head: POSITIVE SEMIOTICS

Thomsen, T. U., \& Sørensen, E. B. (2006). The first four-wheeled status symbol: Pram consumption as a vehicle for the construction of motherhood identity. Journal of Marketing Management, 22(9-10), 907-927.

Wilber, K. (1996). Transpersonal art and literary theory. The Journal of Transpersonal Psychology, 28(1), 63-91.

Wilkinson, R. G., \& Pickett, K. (2010). The Spirit Level: Why More Equal Societies Almost Always Do Better. London: Allen Lane. 
Running head: POSITIVE SEMIOTICS

Positivity $=$ A function of

$\begin{array}{lll}\text { Presence } & \text { Scale Nature }\end{array}$

The extent to which positivity ...

$\ldots$ is inherent in the

$\ldots$ is

... pertains to:

- Sign and/or

- Preferred and/or

- Goodness and/or

- Object and/or

- Sustained across time and/or

- $\quad$ Truth and/or

- Interpretant

- Sustained across people and/or - Beauty and/or

- Sustained across effects and/or - Desirability

- Sustained across structures

Table 1. A heuristic formula for assessing the positivity of a sign-system 